\title{
36 MONTHS SURVIVABILITY AND ITS PREDICTORS IN PATIENTS WITH CHRONIC HEART FAILURE AND DECREASED FRACTION OF LEFT VENTRICULAR EJECTION DEPENDING ON SEX
}

\author{
Leonid Voronkov \\ Department of heart failure \\ National Scientific Center "M. D. Strazhesko of NAMS of Ukraine" \\ 5 Narodnogo Opolchennya str., Kyiv, Ukraine, 03151 \\ Elena Filatova \\ Department of heart failure \\ National Scientific Center "M. D. Strazhesko of NAMS of Ukraine" \\ 5 Narodnogo Opolchennya str., Kyiv, Ukraine, 03151 \\ Alina Lyashenko \\ Department of heart failure \\ National Scientific Center "M. D. Strazhesko of NAMS of Ukraine” \\ 5 Narodnogo Opolchennya str., Kyiv, Ukraine, 03151 \\ Natalya Tkach \\ Department of heart failure \\ National Scientific Center "M. D. Strazhesko of NAMS of Ukraine" \\ 5 Narodnogo Opolchennya str., Kyiv, Ukraine, 03151 \\ Pavel Babych \\ State Expert Center of Ministry of Health of Ukraine \\ 7 Grushevskogo str., Kyiv, Ukraine, 01601
}

\footnotetext{
Abstract

Aim of the work: to compare survivability parameters during 36 months and their predictors among men and women with chronic heart failure and decreased fraction of left ventricular ejection.

Materials and methods: the research included 356 patients with CHF (NYHA II-IV) with decreased LVEF $<40 \%$, 18-75 years old. Using Kaplan-Meier method, there was analyzed the survivability in men and women during 36 months, then there were analyzed independent factors that influenced survivability terms depending on sex using the multiple logistic regression.

Results. Our analysis of the survivability of patients with CHF with decreased LVEF demonstrated that the cumulative survival after 3 years of observation was 49 and $51 \%$ for men and women, respectively. The curves of 36 months survivability didn't reliably differ. At the analysis of factors, associated with the bad prognosis, there were observed differences between groups of men and women with CHF. Thus, in men the predictors of 36 month survival were: the thickness of the right ventricle wall, size of the right atrium, end-diastolic volume and end-systolic volume of LV, indices of EDV and ESV of LV, urinary acid level, value of LVEF. In women the predictors of survivability during 3 years were the following parameters: BMI, DM type 2 in an anamnesis, end-diastolic size of LV, end-systolic size of LV, blood glucose level, LVEF.

Conclusion. The survivability of men and women with CHF with decreased LVEF during 36 months didn't reliably differ and was 49 and $51 \%$ respectively. But predictors of the lethal outcome in men and women essentially differed during 36 months, and their number is essentially higher in men.
}

Keywords: heart failure, survivability, predictors, sex.

\section{Introduction}

Chronic heart failure (CHF) is the one of most unfavorable complications of cardio-vascular diseases in the prognostic aspect that has a tendency to the steady prevalence growth $[1,2]$. Accord- 
ing to the data of epidemiologic studies, the prevalence of clinically expressed CHF (of II-IV functional class in NYHA) in Ukraine is near 1 million people [3] Essential successes in decreasing mortality from CHF in developed countries were achieved mainly due to the introduction of modern methods of this syndrome treatment into practice and the progress in the care organization [4]. Last time works, devoted to differences of the clinical image and course of CHF depending on sex, appeared [5]. Thus, it was demonstrated, that MI was more seldom revealed in an anamnesis of women with $\mathrm{CHF}$, arterial hypertension (AH) frequency and arterial pressure were higher at admission to hospital; in men were more often registered atrial fibrillation, ventricular premature beats, block of the right branch of His bundle [6]. There are also data that CHF of II FC was more often diagnosed in men, and among women - III FC according to NYHA [7]. There is observed also the quicker progression of CHF in men comparing with women [8]. The possibilities of individual prognostication of CHF course remain limited, because the main prognostic markers reflect patients' survivability without taking into account their sex [9]. So, the interest to gender aspects of CHF, including questions of clinical prognostication on cohorts of men and women taking into account prognosis-associated factors, essentially grows [10]. Based on it, the study of survivability predictors of patients with $\mathrm{CFH}$ and decreased left ventricular ejection fraction (LVEF) remains urgent.

\section{Aim of research}

The comparison of parameters of 36 months survivability and their predictors among men and women with CHF and decreased LVEF.

\section{Materials and methods}

The research included 356 patients with CHF (NYHA II-IV) with decreased LVEF $<40 \%$, 18-75 years old (mean age 62,0 18,0 ). Among them 259 men and 97 women, who were at the stationary treatment at the department of heart failure of MI "Institute of cardiology, named after M. D. Stargesk" NAMS of Ukraine in 2010-2013 with the further observation in the ambulatory group. The date of the first general clinical examination was taken As a start point of the observation. $88 \%$ of examined patients had the concomitant arterial hypertension (AH), $241(68 \%)$ had the constant form of atrial fibrillation (AF), 111 (31\%) - myocardium infarction in an anamnesis (MI), 48 (13\%) - disorder of cerebral blood circulation in an anamnesis, 111 (31\%) - diabetes mellitus (DM) type 2, 82 (23\%) chronic obstructive pulmonary disease (COPD), 72 (20\%) - anemia of I degree.

The research didn't include patients with valvular diseases, inflammatory heart lesion, acute ischemic heart disease (AIHD), stroke or transitory ischemic attack less 6 months, oncologic, endocrine (in particular, insulin-dependent DM), chronic, infectious diseases, and also nephrological disease (chronic pyelonephritis, chronic glomerulonephritis, renal amyloidosis).

The diagnosis of the main disease was set on the base of the general clinic examination, special instrumental and laboratory research methods. CHF was diagnosed according to recommendations of its diagnostics and treatment by the Association of cardiologists of Ukraine, agreed with analogous recommendations of the European community of cardiologists [11].

Obligatory methods of the examination of patients included: echocardiography, according to the standard method [12], routine electrocardiography, standard laboratory analyses (general clinic and biochemical), according to existent standards of diagnostics [10], realized on the base of the biochemical laboratory of MI "Institute of cardiology, named after M. D. Stargesk" NAMS of Ukraine. All patients underwent the treatment according to existent standards of the European community of cardiologists [11] that included: diuretics, beta-adrenoblockers, inhibitors of the angiotensin transforming enzyme (IATE) and others.

The statistical processing of results was carried out using the package of applied programs SPSS 13.1 and Excel [13, 14]. The determination of independent factors, influencing patients' survivability, was realized using Cox regression, survivability curves construction - by Caplan-Meyer method, descriptive statistics methods $[13,14]$. Independent survivability predictors were determined in each separately formed model. The significance level for statistical criteria was taken as 0,05 . 


\section{Results of research}

Our analysis of survivability of patients with CHF with decreased LVEF demonstrated that the cumulative survival after 3 years of observation was 49 and $51 \%$ for men and women, respectively $(p=0,137)$. The graph of the cumulative survival is presented on Fig. 1 .

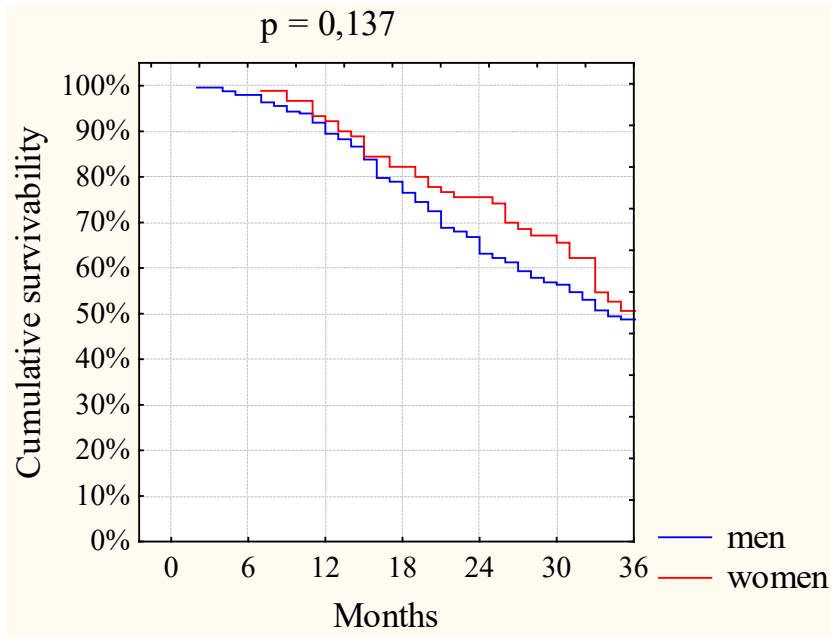

Fig. 1. Survivability curves of patients with CHF and decreased LVEF during 36 months

The search for 39 months survivability predictors depending on sex was carried out using Cox regression (univariant analysis). At the analysis of factors, associated with the bad prognosis, we observed essential differences between men and women with CHF. Thus, in men the predictors of 36 month survival were: the thickness of the right ventricle wall, size of the right atrium, end-diastolic volume and end-systolic volume of LV, indices of EDV and ESV of LV, urinary acid level, value of LVEF. As we can see on table 1 the most important were: the thickness of RV wall, RA size, LV ESVI value.

Table 1

Survivability predictors in men with CHF and decrease LNEF during 36 months

\begin{tabular}{|c|c|c|c|c|c|}
\hline \multirow{2}{*}{ Variable (covariant) } & \multirow{2}{*}{ P-value } & \multirow{2}{*}{ OR } & \multirow{2}{*}{$\beta$} & \multicolumn{2}{|c|}{$95,0 \%$ RI for $O R$} \\
\hline & & & & $\mathbf{L L}$ & HL \\
\hline RV wall thickness & 0,039 & 1,524 & 0,421 & 1,021 & 2,275 \\
\hline RA size & 0,012 & 1,660 & 0,507 & 1,115 & 2,471 \\
\hline LV ESVI & 0,001 & 1,007 & 0,007 & 1,003 & 1,011 \\
\hline LV EDVI & 0,039 & 1,004 & 0,004 & 1,000 & 1,007 \\
\hline LV ESV & 0,002 & 1,003 & 0,003 & 1,001 & 1,005 \\
\hline LV EDV & 0,051 & 1,002 & 0,002 & 1,000 & 1,003 \\
\hline Urinary acid level & 0,007 & 1,001 & 0,001 & 1,000 & 1,002 \\
\hline LVEF & 0,000 & 0,943 & 0,058 & 0,925 & 0,963 \\
\hline
\end{tabular}

Note: $L V E S V$ - end-systolic volume of the left ventricle. RV - right ventricle; $L V E D V$ - end-diastolic volume of the left ventricle. $R A$-right atrium; EDVI-index of end-diastolic volume of the left ventricle; ESVI-index of end-systolic volume of the left ventricle; $L V E F$ - left ventrical ejection fraction 
There was observed no statistically important influence on the survivability of such factors as: age, HF duration, MI in an anamnesis, body mass index (BMI), constant or persisting form of AF, thickness of left atrial walls, levels of glucose, cholesterol, creatitine of blood, speed of glomerular filtration. The presence of COPD or DM type 2 in an anamnesis also didn't influence men's survivability during 36 months.

In women the predictors of the survivability during 3 years were the following parameters: BMI, DM type 2 in an anamnesis, end-diastolic size (EDS) of LV, end-systolic size (ESS) of LV, blood glucose level, end-systolic volume (ESV) of LV, end-diastolic volume (EDV) of LV, LVEF (Table 2).

Table 2

Survivability predictors in women with CHF and decreased LVEF during 36 months

\begin{tabular}{|c|c|c|c|c|c|}
\hline \multirow{2}{*}{ Variable (covariant) } & \multirow{2}{*}{ P-value } & \multirow{2}{*}{ OR } & \multirow{2}{*}{$\beta$} & \multicolumn{2}{|c|}{$95,0 \%$ RI for OR } \\
\hline & & & & $\mathbf{L L}$ & HL \\
\hline BMI & 0,006 & 2,137 & 0,033 & 1,239 & 3,686 \\
\hline DM II type & 0,048 & 1,640 & 0,495 & 1,004 & 2,679 \\
\hline LV EDS & 0,002 & 1,440 & 0,044 & 1,015 & 1,740 \\
\hline LV ESS & 0,012 & 1,413 & 0,346 & 1,079 & 1,850 \\
\hline Blood glucose level & 0,002 & 1,186 & 0,171 & 1,067 & 1,319 \\
\hline LV ESV & 0,037 & 1,004 & 0,004 & 1,000 & 1,008 \\
\hline LV EDV & 0,012 & 1,003 & 0,003 & 0,999 & 1,006 \\
\hline LVEF & 0,000 & 0,941 & 0,061 & 0,910 & 0,972 \\
\hline
\end{tabular}

Note: LV EDS - end-diastolic size of the left ventricle. LVEF - left ventricular ejection fraction; LV ESS end-systolic size of the left ventricle; BMI-body mass index; LV ESV-end-systolic volume of the left ventricle; DM-diabetes mellitus; LV EDV-end-diastolic volume of the left ventricle

Other factors had no reliable influence on women's survivability during 36 months.

\section{Discussion of research results}

Due to numerous studies such as: Framingham Study, Nurses' Health Study, Lipid Research Clinic Study, there was form an opinion as to the more favorable survivability prognosis among women with CHF [15]. At the same time, one must take into account that in aforesaid works was not usually considered HF type with decreased or preserved LVEF [16]. It must be supposed, that the better women's survivability in these studies was obtained at the expanse of more number of individuals with CHF and preserved LVEF among them, that, on the one side prevails among women, on the other one is characterized with a better prognosis [17, 18]. Our analysis testifies that in the population of patients with CHF with decreased LVEF $(<40 \%)$ the prognosis of 3 year survival didn't essentially differ depending on sex. At the same time there were revealed the differences of the lethal outcome occurrence in men and women that possibly must be taken into account at patients' dispensary treatment. It's interesting, that in male patients the leading predictors of the lethal outcome reflect the degree of heart remodeling (RV thickness, LV sizes, LV ESVI value). It is agreed with literary data about the more men's inclination to dilatation and fibrosis formation $[19,20]$. In women the most important lethal outcome predictors are the metabolism indicators 
(BMI, DM in an anamnesis) that may be explained by more number of DM and pulmonary dysfunction cases among them comparing with men (41,6\% against 27,4\% $\mathrm{p}=0,012$, and $60,8 \%$ against $37,7 \% \mathrm{p}<0,001)$ respectively. The obtained data open the certain perspective for optimizing dispensary observation of this category of patients.

\section{Conclusions}

1. The survival of men and women with CHF and decreased LVEF during 36 months didn't reliably differ and was 49 and $51 \%$ respectively.

2. According to the results of Cox univariant model construction, the predictors of 3 year survival in men were: the thickness of the right ventricle wall, size of the right atrium, end-diastolic volume and end-systolic volume of LV, indices of EDV and ESV of LV, urinary acid level, value of LVEF.

3. In women the predictors of survivability during 3 years were the following parameters: BMI, DM type 2 in an anamnesis, end-diastolic size of LV, end-systolic size of LV, blood glucose level, LVEF.

4. The obtained results may be used for the optimization of dispensary observation of patients with CHF.

\section{References}

[1] Voronkov, L. G. (2012). A patient with CHF in Ukraine: an analysis of the data of the population of patients surveyed in the framework of the first national study UNIVERS. Sertseva nedostatnist [Heart Failure], 2, 6-13.

[2] Drozdova, I. V., Vasylieva, L. O., Babets, A. A. (2016). Tserebro-vaskuliarni khvoroby v Ukraini: do pytannia analizu ta prohnozuvannia. East European Scientific Journal, 6 (10), 8-12.

[3] Kovalenko, V. M., Dorogoy, A. P. (2016). Sertsevo-sudinn hvorobi: medichno-sotsialne znachennya ta strategiya rozvitku kardiologiyi v Ukrayini. Ukrayinskiy kardiologichniy zhurnal [Ukrainian Cardiology Journal], 3, 5-14.

[4] Mozaffarian, D., Benjamin, E. J., Go, A. S., Arnett, D. K., Blaha, M. J., Cushman, M. et. al. (2015). Heart Disease and Stroke Statistics-2015 Update. Circulation, 131 (4), 29-322. doi:10.1161/ cir.0000000000000152

[5] Gastelurrutia, P., Gastelurrutia, M. A., Faus, M. J., Bayes-Genis, A. (2012). Common health problems management uncertainties in heart failure: a qualitative study. Farmacia hospitalaria, 36 (6), 498-505.

[6] Bakhshaliev, A. B., Dadashova, G. M., Bakhshalieva, G. I. (2015). Gender-related features of risk factors for, and age- and gender-related differences in the severity and genesis of chronic heart failure. Terapevticheskii Arkhiv, 87 (4), 13-18. doi: 10.17116/terarkh20158713-18

[7] Dadashova, G. M. (2015). Gender specific features of chronic heart failure. Klinicheskaya meditsina [Clinical Medicine], 1, 71-75.

[8] Khalid, A., Bhatti, S. K., Al-Amoodi, M. (2012). Clinical factors associated with left ventricular ejection fraction disparity in patients with left ventricular dysfunction undergoing multimodality imaging. Missouri Medicine, 109 (6), 489-492

[9] Liu, M., Lee, A. P., Sun, J. P. et. al. (2012). Risk stratification for 1 year mortality in patients with heart failure and normal ejection fraction. European Heart Journal, 33 (1), 518 - 519.

[10] O’Connor, C. M., Abraham, W. T., Albert, N. M., Clare, R., Gattis Stough, W., Gheorghiade, M. et. al. (2008). Predictors of mortality after discharge in patients hospitalized with heart failure: An analysis from the Organized Program to Initiate Lifesaving Treatment in Hospitalized Patients with Heart Failure (OPTIMIZE-HF). American Heart Journal, 156 (4), 662-673. doi: 10.1016/j.ahj.2008.04.030

[11] Recommendations on the diagnosis and treatment of chronic heart failure of the Association of Cardiologists of Ukraine and the Ukrainian Association of Cardiac Insufficiency (2012). Sertseva nedostatnist [Heart Failure], 3, 60-96. 
[12] Kovalenko, V.N. (Ed.) (2008). The Cardiology Guide. National Scientific Center «M. D. Strazhesko of NAMS of Ukraine». Kyiv: MORION, 1424.

[13] Petri, A., Sebin, K. (2003). Medical Statistics at a Glance. Kyiv: GEOTAR-MED, 143.

[14] Rebrova, O. Yu. (2002). Statistichniy analiz medichnih danih. Zastosuvannya paketu prikladnih program STATISTICA. Moscow: Medif Sfera [Medif Sphere], 312.

[15] Buring, J. E. (2000). Women in Clinical Trials - A Portfolio for Success. New England Journal of Medicine, 343 (7), 505-506. doi: 10.1056/nejm200008173430711

[16] Aleksander, K., Klabnik, K., Murin, Ya. (2013). Chronic Heart Failure in women. Liki Ukrayini [Medicines of Ukraine], 7, 80-83.

[17] Klapholz, V. (2004). Hospitalization for heart failure in the presence of a normal left ventricular ejection fraction: results of the New York. Heart Failure Registry, 43, 1432-1438.

[18] Tsuchihashi-Makaya, M., Hamaguchi, S., Kinugawa, S., Yokota, T., Goto, D., Yokoshiki, H. et. al. (2009). Characteristics and Outcomes of Hospitalized Patients With Heart Failure and Reduced vs Preserved Ejection Fraction. Circulation Journal, 73 (10), 1893-1900. doi: 10.1253/circj.cj-09-0254

[19] Regitz-Zagrosek, V., Oertelt-Prigione, S., Seeland, U., Hetzer, R. (2010). Sex and Gender Differences in Myocardial Hypertrophy and Heart Failure. Circulation Journal, 74 (7), 1265-1273. doi: 10.1253/ circj.cj-10-0196

[20] Figueredo, V. M., Camacho, S. A. (1994). Basic mechanisms of myocardial dysfunction. Current Opinion in Cardiology, 9 (3), 272-279. doi: 10.1097/00001573-199405000-00003 